\title{
Economic impact of polyherbal mixtures containing choline, lysine and methionine on milk production and health of dairy cows
}

\author{
Nora Idolina Ortega Alvarez', Germán David Mendoza Martínez', Ricardo Barcena Gama², \\ Pedro Abel Hernández García ${ }^{3}$, Enrique Espinosa Ayala ${ }^{3}$, José Antonio Martínez García', \\ Adrian Gloria Trujillo ${ }^{1 *}$
}

\begin{abstract}
${ }^{1}$ Universidad Autónoma Metropolitana Xochimilco, Calzada del Hueso 1100. Ciudad de México. 04960. México, ${ }^{2}$ Colégio de Postgraduados Montecillo. Carretera México- Texcoco, Km. 36.5, Texcoco. 56264. Estado de México, ${ }^{3}$ Centro Universitario UAEM Amecameca, Universidad Autónoma del Estado de México, km 2.5. Carretera Amecameca-Ayapango, 56900, Amecameca, México
\end{abstract}

\section{A B S T R A C T}

The objective of this study was to evaluate the economic impact of supplementing dairy cows with mixtures of polyherbal products supplying conjugates of choline (BioCholine, BC), lysine (OptiLysine, L) and methionine (OptiMethionine, M), considering the costs of veterinary treatments, the nutraceutical effects of the mixtures, the partial cost and returns of milk production. Eighty postpartum Holstein cows were randomly assigned to individually receive. The pellets no containing (Control, 20 cows) and containing polyherbal products (g/d) (BC20, 19 cows; BC40, 17 cows; $\mathrm{BC} 20+\mathrm{L} 40+\mathrm{M} 20,12$ cows, and BC40 + L80 + M40, 12 cows) were offered to cows during the milking through automatic feeders in the course of 90 days in a commercial farm. Treatment costs were grouped in terms of antibiotics, healing, anti-inflammatories, glucogenics, hormonal, intra-mammary treatments, restorative and vitamins. Milk production was not affected $(P>0.05)$ by polyherbal additives but there were numerical differences in the number of treatments and costs; animal health cost per cow showed a high variation coefficient (average 347\%). Cows receiving BC40 and BC20 $+\mathrm{L} 40+\mathrm{M} 20$ had reduced animal health cost per cow but only the treatment BC40 showed residual effects post experiment with an economic improvement of $2.1 \%$ over the control group, showing benefits associated to a reduction in the number of doses with antibiotics and doses of immune-stimulants. Cows receiving BC40 had the best milk yield numerically in combination with the lower number of animal health costs which resulted in the highest income.

Keywords: Dairy cow; Economic analyses; Feed plant additive; Health; Milk production

\section{INTRODUCTION}

Feed plant additives may represent an alternative means to improve health and production in dairy cattle but it is necessary to identify effective products, adequate dosage and optimal conditions to obtain the benefits (Frankič et al., 2009). Some polyherbal mixtures with conjugates of choline (Cañada et al., 2018) and herbal methionine have improved milk yield in dairy cattle (Mendoza et al., 2020). The conventional supplementation of ruminally protected nutrients (amino acids or choline) have demonstrated that they can improve milk yield (Cho et al., 2007; Mohsen et al., 2011), however, increasing milk yield may also increase metabolic problems and other production diseases and reduce fertility (Oltenacu and
Broom, 2010), which should be considered in economic analyses.

Some polyherbal products have shown improvement in fertility and reduction of mastitis but do not present economic analysis (Gutiérrez et al., 2019), however, it can be hypothesized that these effects could be profitable. The economic impact of mastitis is significant in direct and indirect costs; it is estimated that per clinical case of mastitis the losses can be from USD \$ 128 to 444 (Rollin et al., 2015; Cha et al., 2011; Huijps et al., 2008). The improvement in fertility at the first service which could reduce the calving interval; the estimated losses due to increasing the calving interval are in the range from USD $\$ 5.77$ to $6.11 / \mathrm{cow} /$ day (De Vries, 2006).

\footnotetext{
${ }^{*}$ Corresponding author:

Adrian Gloria Trujillo, Universidad Autónoma Metropolitana Xochimilco, Calzada del Hueso 1100. Ciudad de México. 04960. México.

E-mail: ingagt86@gmail.com
} 
Feed plant additives may consist of extracts, mixtures of plants or mixtures of specific parts of these plants. Complete plants contain the most molecules or nutrients that are actively responsible for their biological effects (Frankič et al., 2009). Certain studies supplementing herbal mixtures to dairy cattle have demonstrated some effects on rumen fermentation without significant impacts in milk production (Lejonklev et al., 2016; Kolling et al., 2018) whereas in other studies polyherbal mixtures with nutrients such as phosphatidylcholine (Cañada et al., 2018) along with herbal methionine have improved milk yield (Mendoza et al., 2020) and health in dairy cattle (Gutiérrez et al., 2019).

Information suggesting that synthetic products can provide additional nutrients for high yielding dairy cows is abundant (Patton, 2010; Pinotti et al., 2010; Sales et al., 2010; Awawdeh, 2016). However, in some countries, widespread usage of these bypass products by milk producers may not be common because cost effectiveness is small. On the other hand, reports of production units using nutrient polyherbal mixtures are scarce.

The knowledge of relative profitability for supplementing dairy cows with a polyherbal mixture additive based on veterinary costs is an important issue for decision making in a dairy farm. Therefore, the objective of this study was to evaluate the economic impact of supplementing dairy cows with mixtures of polyherbal products supplying conjugates of choline (BioCholine, BC), lysine (OptiLysine, L) and methionine (OptiMethionine, $\mathrm{M}$ ), considering the costs of veterinary treatments, the nutraceutical effects of the mixtures, the partial cost and returns of milk production.

\section{MATERIAL AND METHODS}

\section{Experimental data}

The experiment was conducted at the Don Bosco Dairy Farm located in the municipality of San Miguel de Allende, State of Guanajuato, with a mean temperature of $19.5^{\circ} \mathrm{C}$ and an annual rainfall of $545 \mathrm{~mm}$. Eighty multiparous lactating dairy Holstein cows were fed a basal $\operatorname{diet}(18.3 \% \mathrm{CP}$ and $1.35 \mathrm{Mcal} / \mathrm{kg} \mathrm{NEl})$ with $48 \%$ forage (alfalfa hay, alfalfa silage, corn silage) and $52 \%$ concentrate (corn grain, barley grain, cane molasses, and premix). Before starting the experiment, one hundred cows with homogenous conditions in milk production and health (Fig. 1a) were adapted 15 days postpartum to the pellet and selected to polyherbal evaluation between the second and third lactation without exceeding 30 days post calving (Nebel, 2011).

In order to evaluate the effect of herbals on peak milk production and reproductive efficiency, the experiment
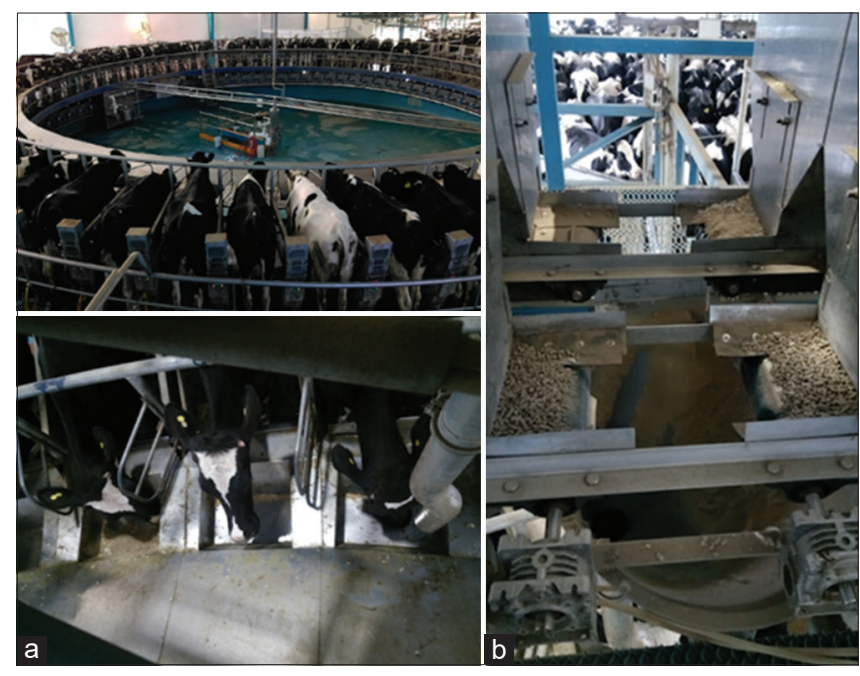
Fig 1. Cows during milking receiving the experimental pellets: a) Group
milking parlor; b) Automatic feeder system; c) Cows consuming the pellets.

extended to 120 days post-calving, so cows $(4 \pm 0.57$ years old) were randomly distributed to one of the five experimental treatments, from day 30 post calving up to 90 days to provide choline (BioCholine, BC), lysine (OptiLysine, L) and methionine (OptiMethionine, M) conjugates distributed ( $\mathrm{g} / \mathrm{cow} /$ day) as follow: control (C) $(n=20)$, BC20 $(n=19), B C 40(n=17)$, BC20-L40-M20 $(n=12)$ and BC40-L80-M40 $(n=12)$. The consumption of the pellet with mixture was confirmed individually and the number of replications represents the number of cows adapted to pellet feeding.

Polyherbal mixtures were from Nuproxa Mexico, Nuproxa Switzerland and Indian Herbs. The pellet (Fig. 1b) ingredient proportion were prepared according treatment (BC20, BC40, BC20-L40-M20 and BC40-L80-M40), and was composed of soybean hulls and wheat bran (both ingredients with the same proportion: $20,15,10$ and $5 \%$ ), wheat grain $(48.67,52,52$ and $52 \%)$, cane molasses ( $5 \%$ for all treatments), sodium bentonite (1\% for all treatments) and Sucram ${ }^{\circledR}$ (400 g/Ton: Flavoring, Pancosma, México). The cows assigned to one of the treatments received the corresponding amount of pellets automatically (Fig. 1c) when they were identified in the milking by their pedometer. This individual feeder was linked to 4 hoppers containing the pellet with the corresponding polyherbal mixture for each treatment, therefore, the consumption of pellets for each cow during milking was monitored. The pellets were manufactured in a commercial animal feed plant (ALBASA, Guanajuato, Mexico). The feeding with the rest of the ingredients of the diet was carried out in the feeders of the pens.

Samples of OptiLysine and dry OptiMethionine were analyzed for lysine and methionine using Ultra Performance 
Liquid Chromatography technique (UPLC, Szkudzińska et al., 2017). OptiLys contained $11.19 \mathrm{~g}$ Lys/100 g protein and OptiMet $5.23 \mathrm{~g}$ Met/100 g protein. Natural choline conjugates in BioCholine was analyzed by HighPerformance Thin-Layer Chromatography (HPTLC, Kupke and Zeugner, 1978). The BioCholine contained $1.6 \%$ of natural choline conjugated form such as phosphatidylcholine and equivalents. Pellets were formulated in order to provide amino acid (Rulquin et al., 1994; Lara et al., 2006; Ordway and Aines, 2010) and choline requirements (Richard et al., 2016; Cañada et al., 2018).

Milk production was recorded daily using the automatic equipment MDS-Milk ${ }^{\circledR}$ (Mlsna Dairy Supply, Inc.) (Rutten et al., 2013; Antanaitis et al., 2015). Individual veterinary treatments (Fonseca et al., 2004) and general information to perform an economic analysis, were obtained from the database for each cow during the experimental feeding period (day 30 to 120) and after the assay (day 120 to day 210).

The economic efficiency was calculated as the relationship between the price of milk produced pre, during and postexperimentation, the cost of supplementation with pellets, as well as the cost of veterinary treatments (divided as antibiotics, intramammary and anti-inflammatory) for cow per day, according to Figures of 2017 (US $=20$ Mexican pesos) (Mohsen et al., 2011). The sale price of milk was 0.3425 US\$ per liter at the time of the study.

\section{Statistical analysis}

Data were analyzed with R software package fdANOVA (Górecki and Smaga, 2019). Milk production was analyzed as a completely randomized design and number of veterinary treatments and costs were tested for normality and analyzed with non-parametric Kruskall-Wallis test (Dalcq et al., 2017).

\section{RESULTS}

In the experimental period, the BC20-L40-M20 group substantially reduced the cost of antibiotics and intramammary treatments per cow. The post-experiment evaluation (residual effects) showed that the BC40 groups had lower antibiotic treatments and BC40-L80-M40 had the lowest intra-mammary treatments after the control group (Table 1). The accumulated veterinary treatments per cow show that groups with BC40 and BC20-L40-M20 reduced the number of treatments, representing a reduction of 22.77 and $19.61 \%$ respectively, but the treatments with BC20 and BC40-L80-M40 increased the treatments in 16.0 and $5.3 \%$ respectively in comparison to the control group.
Milk production was not affected $(P>0.05)$ by feed plant additive combinations during the experiment or by residual effects post-experimentation (Table 2). The differences in number of treatments and incidence of disease showed high variation which repercussed in the animal health costs and statistical differences were not detected despite the observation that during the experimental period $\mathrm{BC} 20$ L40-M20 reduced substantially costs in comparison to other treatments (Table 2).

The pellet cost was influenced by the dose and number of herbal compounds included but income from milk was similar among treatments. Cows consuming $40 \mathrm{~g}$ of $\mathrm{BC}$ in the experimental period had the highest numerical milk production followed by the control group and after the experiment resulted in a $2.1 \%$ income improvement (Table 2) indicating also a residual effect on animal health after the experiment. The treatment with BC20L40-M20 resulted in a moderate-income improvement $(0.79 \%)$.

\section{DISCUSSION}

Most of the economic studies in dairy cattle agree that feeding costs are the major component of producing a liter of milk, accounting for about 60 to $70 \%$ of the cost (Tatlidil and Akturk, 2009; Akturk et al., 2010; Dubey et al., 2017) while labor cost was second, representing 0.7 to $6.5 \%$ of the cost (Türkyilmaz and Aral, 2002). In contrast, antibiotic and veterinary costs vary between countries because the proportion of costs of production may vary depending on the country and production system. Nevertheless, there is a general agreement that mastitis control is a major contributor to costs related to animal health (Halasa et al., 2007) and may be between 11 to $22 \%$ of veterinary costs but is estimated to cause economic losses two times more due to reduced yield and discarded milk (Seegers et al., 2003). The economic impact may be greater if the costs of syringes and fees of veterinary doctors are considered (Ghule et al., 2012).

In the evaluation conducted, the costs associated with antibiotics, anti-inflammatories and intra-mammary treatments together accounted for $81 \%$ of animal health costs per cow. Results of some treatments (Jouany and Morgavi, 2007) showed that some plant feed additives can reduce the negative economic impact of general diseases with additional advantages by reducing the development of drug-resistant microbes. The polyherbal products used in this evaluation have been used in sheep (Godínez-Cruz et al., 2015, Rodríguez-Guerrero et al., 2018, MartínezAispuro et al., 2019) and in dairy cows (Cañada et al., 2018; Mendoza et al., 2020) and in a multiyear evaluation 
Table 1: Cost of veterinary treatments (US\$/cow) for evaluation of feed plant additive in a commercial herd

\begin{tabular}{|c|c|c|c|c|c|c|c|}
\hline \multicolumn{8}{|c|}{ Treatments $^{\mathrm{a}}$} \\
\hline & C & $\mathrm{BC20}$ & $\mathrm{BC} 40$ & BC20-L40-M20 & BC40-L80-M40 & $\mathrm{CV}^{\mathrm{b}}(\%)$ & $P$-value \\
\hline \multicolumn{8}{|l|}{ Experimental period (90 days) } \\
\hline Antibiotics & 30.34 & 30.14 & 17.52 & 5.83 & 47.65 & 239.12 & 0.80 \\
\hline Healing & 0.32 & 1.89 & 0.00 & 0.00 & 2.54 & 490.39 & 0.55 \\
\hline Anti-inflammatories & 8.43 & 13.75 & 3.81 & 2.02 & 14.00 & 234.19 & 0.43 \\
\hline Glucogenics & 0.00 & 0.00 & 0.07 & 0.00 & 0.00 & 894.43 & 0.45 \\
\hline Hormonal & 3.16 & 4.46 & 4.52 & 3.47 & 5.12 & 70.31 & 0.47 \\
\hline Intra-mammary treatments & 6.64 & 7.34 & 3.31 & 0.38 & 11.93 & 296.30 & 0.42 \\
\hline Restorative & 1.46 & 3.98 & 1.86 & 0.59 & 5.62 & 255.60 & 0.21 \\
\hline Vitamins & 3.35 & 3.91 & 2.06 & 0.26 & 5.84 & 302.11 & 0.37 \\
\hline \multicolumn{8}{|c|}{ Post experimental period (90 days) } \\
\hline Antibiotics & 17.08 & 31.30 & 14.99 & 26.18 & 25.96 & 197.47 & 0.82 \\
\hline Healing & 0.00 & 0.00 & 0.00 & 0.00 & 0.00 & - & - \\
\hline Inflammatories & 10.35 & 12.87 & 5.77 & 9.84 & 6.64 & 182.30 & 0.95 \\
\hline Glucogenics & 0.21 & 0.00 & 0.52 & 0.43 & 0.00 & 480.34 & 0.35 \\
\hline Hormonal & 0.72 & 0.66 & 1.52 & 0.90 & 0.90 & 213.94 & 0.52 \\
\hline Intra-mammary treatments & 2.73 & 6.11 & 4.72 & 5.43 & 3.05 & 235.84 & 0.65 \\
\hline Glucogenics & 6.01 & 7.57 & 5.05 & 13.22 & 2.76 & 177.39 & 0.44 \\
\hline Vitamins & 1.96 & 2.24 & 0.55 & 3.04 & 0.30 & 245.39 & 0.45 \\
\hline
\end{tabular}

${ }^{a}$ C: control, BC: conjugates of choline (BioCholine), L: conjugates of lysine (OptiLysine), M: conjugates of methionine (OptiMethionine), ${ }^{\mathrm{b}}$ Coefficient of variation.

Table 2: Milk production and economic efficiency of Holstein cows supplemented with choline conjugates, methionine and lysine herbal

\begin{tabular}{|c|c|c|c|c|c|c|c|}
\hline & \multicolumn{5}{|c|}{ Treatments $^{\mathrm{a}}$} & \multirow[b]{2}{*}{$\mathrm{CV}^{\mathrm{b}}(\%)$} & \multirow[b]{2}{*}{$P$-value } \\
\hline & C & $\mathrm{BC20}$ & BC40 & BC20-L40-M20 & BC40-L80-M40 & & \\
\hline \multicolumn{8}{|l|}{ Experimental period (90 days) } \\
\hline Milk yield (kg/day) & 40.01 & 36.73 & 40.16 & 38.98 & 38.18 & 15.38 & 0.40 \\
\hline Pellet+Additive/cow & 0.103 & 0.185 & 0.369 & 0.424 & 0.847 & & \\
\hline Animal health cost $($ US $\$$ ) per cow & 53.69 & 65.48 & 33.14 & 12.55 & 92.70 & 225.21 & 0.29 \\
\hline Partial cost (US\$) & 53.79 & 65.67 & 33.51 & 12.97 & 93.55 & & \\
\hline Partial cost (US\$/kg Milk) & 0.74 & 0.56 & 1.20 & 3.00 & 0.41 & & \\
\hline Income of milk yield (US\$/cow/day) & 13.70 & 12.58 & 13.75 & 13.35 & 13.08 & & \\
\hline Income improvement (US\$) & 0.00 & -1.12 & 0.05 & -0.35 & -0.63 & & \\
\hline Income improvement (\%) & 100.00 & -8.20 & 0.37 & -2.57 & -4.57 & & \\
\hline \multicolumn{8}{|l|}{ Post experimental period (90 days) } \\
\hline Milk yield (kg/day) & 34.61 & 32.64 & 36.34 & 35.24 & 34.56 & 21.77 & 0.72 \\
\hline Pellet+Additive per cow & 0.103 & 0.185 & 0.369 & 0.424 & 0.847 & & \\
\hline Animal health cost (US/cow) & 39.06 & 60.74 & 33.12 & 59.04 & 39.62 & 170.29 & 0.99 \\
\hline Partial cost (US) & 39.16 & 60.93 & 33.49 & 59.46 & 40.47 & & \\
\hline Partial cost (US/kg Milk) & 0.88 & 0.54 & 1.09 & 0.59 & 0.85 & & \\
\hline Income of milk yield (US\$/cow/day) & 11.85 & 11.18 & 12.45 & 12.07 & 11.84 & & \\
\hline Income improvement (US\$) & 0.00 & -1.25 & 0.28 & 0.10 & -1.06 & & \\
\hline Income improvement (\%) & 100.00 & -9.56 & 2.10 & 0.79 & -8.10 & & \\
\hline
\end{tabular}

${ }^{a}$ C: control, BC: conjugates of choline (BioCholine), L: conjugates of lysine (OptiLysine), M: conjugates of methionine (OptiMethionine), ${ }^{b}$ Coefficient of variation. c US dollars

reduced abortions, mastitis, respiratory disorders and herd replacement (Gutiérrez et al., 2019).

The information of some metabolites reported in the individual plants from the mixture as well as from other medicinal plants may help to explain the biological effects observed in this evaluation and in the multiyear report. A mixture containing $W$ ithania somnifera, Tinospora cordifolia and Emblica officinalis has been reported to help in the prevention and in the treatment of clinical mastitis (Das et al., 2003) associated with the hydrolysable tannins found in E. officinalis. Ocimum sanctum reduced somatic cell count in dairy cows dosed orally and reduced inflammation (Shafi et al., 2016). Reshi et al (2017) evaluated intra-mammary infusion of Fumaria indica and Adiantum capillus plant extracts against subclinical mastitis finding antibacterial properties. A review of medicinal plants from the Kashmir Himalayas compiled by Mushtaq et al. (2018) indicated that traditional plants have antimicrobial potential against mastitis pathogens. 
One advantage of including polyherbal mixtures is the reduction of antibiotic use and the reduced possibility of achieving the measurable levels of the antibiotic in the milk. Kirchhelle (2018) pointed out that in massive milk collection systems from different farms, the presence of drug residues in a cow's milk could contaminate thousands of liters of milk, therefore antibiotics in milk need to be monitored with sensitive procedures (Cinquina et al., 2003) which according to legal regulations may have economic impact. The presence of natural anti-inflammatories in the polyherbal mixtures favors the animal welfare which is an issue that must be addressed and promoted as a good management practice that reduces metabolic stress and improves quality of life of dairy cows. It would also allow access to the organic markets of milk that may be more profitable.

Polyherbal mixtures did not increase milk production significantly but treatment with $40 \mathrm{~g}$ of BioCholine was profitable. Most nutrient or additive evaluations have focused on obtaining greater profitability per cow by maximizing milk production (Dyaa et al., 2013; Mendoza et al., 2020) but this may be considered a limited vision and focus should instead be directed towards maximizing overall profit (Cho et al., 2007; Dalcq et al., 2017). There are numerous reports supplementing ruminally protected choline confirming that there are dose responses where production can be increased by up to $10 \%$ (Pinotti et al., 2010; Sales et al., 2010). But there are few studies supplementing herbal choline, in one the production of grazing cows increased by $21 \%$ (Cañada et al., 2018) but in high yielding lactating cows an improvement of only $1.57 \%$ was reported (Gutiérrez et al., 2019). There are important differences between the metabolism followed by ruminally protected choline chloride described by De-Veth et al (2016) and total choline conjugates in the polyherbal mixture (Martínez-Aispuro et al., 2019) that do not allow direct comparisons between the two sources that physiologically contribute phosphatidylcholine to the body.

The response observed with polyherbal mixtures with choline could be attributed to the nutrient functions that have been demonstrated to improve the immune-metabolic status in dairy cows (Vailati-Riboni et al., 2017) as well as in the antioxidant capacity (Sun et al., 2016) that has allowed for a reduction in metabolic problems and overall morbidity (Lima et al., 2012). The residual effect of BC40 on milk production could be explained by the antioxidant and immunostimulants properties of herbal additives on the health of the mammary gland (Walkenhorst et al., 2020), by reducing cell death in the milk-secretory epithelium and the long-term negative effects on the lactation in cows with mastitis (Capuco et al., 2003). This coincides with Gutiérrez et al. (2019) who reporting lower incidence of mastitis and higher milk production in cows supplemented with herbal choline in which Mendoza et al (2020) found 4-vinylguaiacol and undecane in the volatile compounds in the polyherbal mixture; the first one has antioxidant properties (Esatbeyoglu et al 2015) and the second antiinflammatories activity (Fa-Liang et al 2017).

Polyherbal mixtures may provide constituents involved in improving ruminal fermentation; BioCholine modified kinetics of in vitro gas production (Rodríguez-Guerrero et al 2018) and the secondary metabolites can have beneficial effects in fermentation by different action mechanisms reviewed by Jouany and Morgavi (2007). However, the increment in costs and lack of response when the herbal products were combined in high doses (BC40-L80-M40), confirms the observation of Jouany and Morgavi (2007) that excessive dosage of secondary metabolites from plants can induce negative responses. Nevertheless, in general most of the studies show beneficial effects of herbs on feed intake, immune functions and health, rumen fermentation and productivity of ruminants (Frankič et al 2009), therefore it is important to continue dose response evaluations of polyherbal products and other feed plant additives.

\section{CONCLUSIONS}

Cows with $40 \mathrm{~g}$ of polyherbal mixture containing conjugates of choline had the best milk yield numerically and the lower number of animal health costs in the post-experimental period which resulted in the lowest animal-health related cost per liter of milk, so nutritionists may be advised to direct attention to feed plant additives as nutraceuticals as they may play an important role in the farm profitability and productivity by improving health.

\section{ACKNOWLEDGEMENTS}

Authors acknowledge Nuproxa Mexico, Indian Herbs and Nuproxa Switzerland for donating the polyherbal mixtures. Thanks, are also extended to Ray Jones for edition and contributions to the manuscript.

\section{Authors' contributions}

All authors participated equally in the design of the experiment, analysis and writing of the manuscript.

\section{REFERENCES}

Akturk, D., Z. Bayramoğlu, F. Savran and F. F. Tatlidil. 2010. The factors affecting milk production and milk production cost. Kafkas Univ. Vet. Fak. Der. 16: 329-335.

Antanaitis, R., V. Žilaitis, A. Kučinskas, V. Juozaitienè and 
K. Leonauskaitè. 2015. Changes in cow activity, milk yield, and milk conductivity before clinical diagnosis of ketosis, and acidosis. Vet. Med. Zoot. 70: 3-9.

Awawdeh, M. S. 2016. Rumen-protected methionine and lysine: Effects on milk production and plasma amino acids of dairy cows with reference to metabolizable protein status. J. Dairy Res. 83: 151-155.

Cañada, L. M. G., E. Meráz-Romero, G. D. Mendoza-Martínez, B. Villagrán-Vélez and D. A. Castillo-Mata. 2018. Efecto del nivel de colina herbal en la producción y composición de leche en ganado lechero en pastoreo. Arch. Latinoam. Prod. Anim. 26: 82.

Capuco, A. V., S. E. Ellis, S. A. Hale, E. Long, R. A. Erdman, X. Zhao and M. J. Paape. 2003. Lactation persistency: Insights from mammary cell proliferation studies. J. Anim. Sci. 81: 18-31.

Cha, E., D. Bar, J. A. Hertl, L. W. Tauer, G. Bennett, R. N. González, Y. H. Schukken, F. L. Welcome and Y. T. Gröhn. 2011. The cost and management of different types of clinical mastitis in dairy cows estimated by dynamic programming. J. Dairy Sci. 94: 4476-4487.

Cho, J., T. R. Overton, C. G. Schwab and L. W. Tauer. 2007. Determining the amount of rumen-protected methionine supplement that corresponds to the optimal levels of methionine in metabolizable protein for maximizing milk protein production and profit on dairy farms. J. Dairy Sci. 90: 4908-4916.

Cinquina, A. L., F. Longo, G. Anastasi, L. Giannetti and R. Cozzani. 2003. Validation of a high-performance liquid chromatography method for the determination of oxytetracycline, tetracycline, chlortetracycline and doxycycline in bovine milk and muscle. J. Chromatogr. A. 987: 227-233.

Dalcq, A. C., Y. Beckers, P. Mayeres and E. Reding. 2017. The feeding system impacts relationships between calving interval and economic results of dairy farms. Animal. 12: 1662-1671.

Das, P. K., M. R. Das, K. C. Acharya and S. K. Ray. 2003. Evaluation of herbal immuno-stimulant "Immu-21" in prevention and treatment of bovine clinical mastitis. Phytomedica. 4: 13-20.

De Veth, M. J., V. M. Artegoitia, S. R. Campagna, H. Lapierre, F. Harte and C. L. Girard. 2016. Choline absorption and evaluation of bioavailability markers when supplementing choline to lactating dairy cows. J. Dairy Sci. 99: 9732-9744.

De Vries, A. 2006. Economic value of pregnancy in dairy cattle. J. Dairy Sci. 89: 3876-3885.

Dubey, M., V. P. Singh, R. K. Pandey and A. K. Chaubey. 2017. Economic analysis of feeding management and milk production at the university dairy farm. Int. J. Curr. Microbiol. App. Sci. 6: 480-486.

Dyaa, E. D. A., B. E. Borhami, K. A. El-Shazly and M. A. Sallam. 2013. Effect of dietary supplementation with fibrolytic enzymes on the productive performance of early lactating dairy cows. J. Agric. Sci. 5: 146-155.

Esatbeyoglu, T., K. Ulbrich, C. Rehberg, S. Rohn and G. Rinbach. 2015. Thermal stability, antioxidant, and anti-inflammatory activity of curcumin and its degradation product 4-vinyl guaiacol. Food Funct. 6: 887-893.

Fa-Liang, A., S. Dong-Mei, L. Rui-Jun, Z. Miao-Miao, Y. Ming-Hua, Y. Yong, K. Ling-Yi and L. Jun. 2017. Walrobsins A and B, wo anti-inflammatory limonoids from root barks of Walsura robusta. Org. Lett. 19: 4568-4571.

Fonseca, L. F. L., P. H. Mazza-Rodrigues, M. Veiga-dos Santos, A. Pinto-Lima and C. de Souza-Lucci. 2004. Supplementation of dairy cows with propylene glycol during the periparturient period: Effects on body condition score, milk yield, first estrus post-partum, beta-hydroxybutyrate, non-esterified fatty acids and glucose concentrations. Cienc. Rural. 34: 897-903.
Frankič, T., M. Voljč, J. Salobir and V. Rezar. 2009. Use of herbs and spices and their extracts in animal nutrition. Acta Agric. Slov. 94: 95-102.

Ghule, A., N. K. Verma, A. K. Cahuhan and P. D. Sawale. 2012. An economic analysis of investment pattern cost of milk production and profitability of commercial dairy farms in Maharashtra. Indian J. Dairy Sci. 65: 329-336.

Godínez-Cruz, J., O. Cifuentes-Lopez, J. Cayetano, H. Lee-Rangel, G. Mendoza, A. Vazquez and A. Roque. 2015. Effect of choline inclusion on lamb performance and meat characteristics. J. Anim. Sci. 93:766.

Gutiérrez, A. R., A. Gutiérrez, C. Sánchez and G. D. Mendoza. 2019. Effect of including herbal choline in the diet of a dairy herd; a multiyear evaluation. Emir. J. Food Agric. 31: 477-481.

Halasa, T., K. Huips, O. Østerås and H. Hogeveen. 2007. Economic effects of bovine mastitis and mastitis management: A review. Vet. Q. 29: 18-31.

Huijps, K., T. J. Lam and H. Hogeveen. 2008. Costs of mastitis: Facts and perception. J. Dairy Res. 75: 113-120.

Jouany, J. P. and D. P. Morgavi. 2007. Use of "natural" products as alternatives to antibiotic feed additives in ruminant production. Animal. 1: 1443-1466.

Kirchhelle, C. 2018. Pharming animals: A global history of antibiotics in food production (1935-2017). Palgrave Commun. 4: 96.

Kolling, G. J., S. C. B. Stivanin, A. M. Gabbi, F. S. Machado, A. L. Ferreira, M. M. Campos, T. R. Tomich, C. S. Cunha, S. W. Dill, L. G. R. Pereira and V. Fischer. 2018. Performance and methane emissions in dairy cows fed oregano and green tea extracts as feed additives. J. Dairy Sci. 101: 4221-4234.

Kupke, I. R. and S. Zeugner. 1978. Quantitative high-performance thin-layer chromatography of lipids in plasma and liver homogenates after direct application of 0.5 -microliter samples to the silica-gel layer. J. Chromatogr. 46: 261-71.

Lara, A., G. D. Mendoza, L. Landois, R. Barcena, M. T. Sánchez-Torres, R. Rojo, J. Ayala and S. Vega. 2006. Milk production in Holstein cows supplemented with different levels of ruminally protected methionine. Livest. Sci. 105: 105-108.

Lejonklev, J., U. Kidmose, S. Jensen, M. A. Petersen, A. L. F. Helwing, G. Mortensen, M. R. Weisbjerg and M. K. Larsen. 2016. Short communication: Effect of oregano and caraway essential oils on the production and flavor of cow milk. J. Dairy Sci. 99: 7898-7903.

Lima, F. S., M. F. Sá Filho, L. F. Greco and J. E. P. Santos. 2012. Effects of feeding rumen-protected choline on incidence of diseases and reproduction of dairy cows. Vet. J. 193: 140-145.

Martínez-Aispuro, J. A., G. D. Mendoza, J. L. Cordero-Mora, M. A. Ayala-Monter, M. T. Sánchez-Torres, J. L. Figueroa-Velasco, G. Vázquez-Silva and A. Gloria-Trujillo. 2019. Evaluation of an herbal choline feed plant additive in lamb feedlot rations. $R$. Bras. Zootec. 48: 20190020.

Mendoza, G. D., M. F. Oviedo, J. M. Pinos, H. A. Lee-Rangel, A. Vázquez, R. Flores, F. Pérez, A. Roque and O. Cifuentes. 2020. Milk production in dairy cows supplemented with herbal choline and methionine. Rev. Fac. UNCUYO. 52: 332-343.

Mohsen, M. K., H. M. A. Gaafar, M. M. Khalafalla, A. A. Shitta and A. M. Yousif. 2011. Effect of rumen protected choline supplementation on digestibility, rumen activity and milk yield in lactating Friesian cows. Slovak J. Anim. Sci. 44: 13-20.

Mushtaq, S. A. M. Shah, A. Shah, S. A. Lone, A. Hussain, Q. P. Hassan and M. N. Ali. 2018. Bovine mastitis: An appraisal of its alternative herbal cure. Microb. Pathog. 114: 357-361.

Nebel, R. L., C. M. Jones and Z. Roth. 2011. Reproduction, events and management mating management: Detection of estrus. 
In: J.W. Fuquay (Ed.), Encyclopedia of Dairy Sciences. $2^{\text {nd }}$ ed. Academic Press, Cambridge, Massachusetts, pp. 461-466.

Oltenacu, P. A. and D. M. Broom. 2010. The impact of genetic selection for increased milk yield on the welfare of dairy cows. Anim. Welf. 19: 39-49.

Ordway, R. and G. Aines. 2010. Feeding lysine: A Nutritionist and Dairy Producer's Perspective. High Plains Dairy Conference. Amarilloc, Texas, pp. 109-116.

Patton, R. A. 2010. Effect of rumen-protected methionine on feed intake, milk production, true milk protein concentration, and true milk protein yield, and the factors that influence these effects: A meta-analysis. J. Dairy Sci. 93: 2105-2118.

Pinotti, L., C. Polidori, A. Campagnoli, V. Dell'Orto and A. Baldi. 2010. A meta-analysis of the effects of rumen protected choline supplementation on milk production in dairy cows. Eaap Sci. Ser. 127: 321-322.

Reshi, I. A., T. K. Sarkar, H. Malik, A. Muhee and S. Shoukat. 2017. Efficacy of Fumaria indica, Nepata cataria and Adianthum capillus crude aqueous extracts in comparison to cefuroxime in sub-clinical cases of bovine mastitis. Int. J. Livest. Res. 7: 100-107.

Richard, C., E. D. Lewis, Z. Yuan-Yuan, J. Asomaning, R. L. Jacobs, C. J. Field and J. M. Curtis. 2016. Measurement of the total choline content in 48 commercial dairy products or dairy alternatives. J. Food Compos. Anal. 45: 1-8.

Rodríguez-Guerrero, V., A. C. Lizarazo, S. Ferrarol, N. Suárez, L. A. Miranda and G. D. Mendoza. 2018. Effect of herbal choline and rumen-protected methionine on lamb performance and blood metabolites. S. Afr. J. Anim. Sci. 48: 427-434.

Rollin, E., K. C. Dhuyvetter and M. W. Overton. 2015. The cost of clinical mastitis in the first 30 days of lactation: An economic modeling tool. Prev. Vet. Med. 122: 257-264.

Rulquin, H., C. Hurtaud and L. Delaby. 1994. Effects of graded levels of rumen-protected lysine on milk production in dairy cows. Ann. Zootech. 43: 246.

Rutten, C. J., A. G. J. Velthuis, W. Steeneveld and H. Hogeveen. 2013. Invited review: sensors to support health management on dairy farms. J. Dairy Sci. 96: 1928-1952.

Sales, J., P. Homolka and V. Koukolová. 2010. Effect of dietary rumen-protected choline on milk production of dairy cows: A meta-analysis. J. Dairy Sci. 93: 3746-3754.

Górecki, S. T. and Ł. Smaga. 2019. fdANOVA: An R software package for analysis of variance for univariate and multivariate functional data. Comput. Stat. 34: 571-597.

Seegers, H., C. Fourichon and F. Beaudeau. 2003. Production effects related to mastitis and mastitis economics in dairy cattle herds. Vet. Res. 34: 475-491.

Shafi, T. A., B. K. Bansal, D. K. Gupta and A. Nayyar. 2016. Evaluation of immunotherapeutic potential of Ocimum sanctum in bovine subclinical mastitis. Turk. J. Vet. Anim. Sci. 40: 352-358.

Sun, F., Y. Cao, C. Cai, S. Li, C. Yu and J. Yao. 2016. Regulation of nutritional metabolism in transition dairy cows: Energy homeostasis and health in response to post-ruminal choline and methionine. PLoS One. 11: e0160659.

Szkudzińska, K., I. Smutniak, J. Rubaj, W. Korol and G. Bielecka. 2017. Method validation for determination of amino acids in feed by UPLC. Accred. Qual. Assur. 22: 247-252.

Tatlidil, F. F. and D. Aktürk. 2009. Comparative analysis of dairy cattle-breeding farms on member and non-member of breeders association. Agric. Syst. 4: 36-40.

Türkyilmaz, M. K. and S. Aral. 2002. Efficiency of resource usage in dairy herds aydin province and their marketing and organizational problems. Kafkas Univ. Vet. Med. J. 8: 41-48.

Vailati-Riboni, M., Z. Zhou, C. B. Jacometo, A. Minuti, E. Trevisi, D. N. Luchini and J. J. Loor. 2017. Supplementation with rumenprotected methionine or choline during the transition period influences whole-blood immune response in periparturient dairy cows. J. Dairy Sci. 100: 3958-3968.

Walkenhorst, M., F. Leiber, A. Maeschli, A. Kapp, A. Spengler-Neff, M. Faleschini, E. Garo, M. Hamburger, O. Potterat, P. Mayer, S. Graf-Schiller and A. Bieber. 2020. A multicomponent herbal feed additive improves somatic cell counts in dairy cows a two stage, multicentre, placebo-controlled long-term on-farm trial. J. Anim. Physiol. Anim. Nutr. 104: 439-452. 